\title{
New Annie and Willie Nelson Professor says award is music to his ears
}

I

n March, singer Willie Nelson and his wife, Annie, put on a benefit concert to raise funds for a stem cell program at The University of Texas Southwestern Medical Center at Dallas. The concert raised $\$ 250,000$, which was used to create a professorship named for Annie and Willie Nelson. The first Nelson Professor is Eric Olson, chairman of the Department of Molecular Biology. The JCI spoke with Olson about the award, his career, and his musical inclinations.

JCI: How were you selected for this award?

Olson: As a developmental biologist, I have a natural interest in stem cell biology, and my lab has initiated some interesting projects on the control of stem cell fates. Second, I love country music, and I think I'm a bigger fan of the genre than any of my colleagues. Since I love Texas and country music and Willie Nelson is an icon of both, being named the Willie Nelson Professor is about as cool as it gets.

JCI: What will this prize money be used for?

Olson: The intention is to enhance the UT Southwestern stem cell program in general, not just my lab. I expect we will use the funds to purchase equipment, support core facilities, and catalyze new projects not yet ready for NIH support.

JCI: Tell us about the research your lab does.

Olson: My lab uses muscle cells as a model to understand the basic mechanisms of development and differentiation. Understanding how a stem cell becomes a specialized cell is a holy grail for developmental biologists. Recently, we've come up with some interesting ideas about how to discover small molecules that may influence the behavior of stem cells as well as [ideas about] how epigenetic mechanisms may participate in stem cell decisions.

JCI: Where do you stand on the controversies surrounding stem cell research?

Olson: I certainly believe embryonic stem cells have great potential in regenerative medicine. But right now, it's mostly just potential. A lot of groundwork needs to be laid. Regarding the ethical issues, I will say that I have solid religious beliefs and try to attend church regularly with my family. In that context, I do not believe stem cells equal human life, and I do not accept the position that using human stem cells to improve human life is unethical. On the contrary, it seems unethical to arbitrarily deny therapies that could potentially improve the human condition. The fact is that if and when embryonic stem cells are shown to cure diabetes or Parkinson's or spinal cord injury - pick your disorder - then the demand will be so great that no politician will be able to stand in the way. In the meantime, there is a lot of interesting science to do.

JCI: What do you consider your greatest scientific accomplishment?

Olson: The greatest accomplishment has been the discovery of numerous master regulators of muscle development. Over the past 20 years, we have discovered many transcription factors that control the fate, differentiation, and patterning of cardiac, skeletal, and smooth muscle cells. We have delineated evolutionarily conserved pathways that control muscle gene expression during development and disease. The real- ization that many developmental regulatory mechanisms are also deployed in the adult heart during pathological remodeling kindled my interest in [exploiting] our understanding of muscle development to develop novel drugs to treat cardiovascular diseases. Several years ago, I cofounded Myogen Inc., which [translates] basic science into drugs. This has allowed me to do something practical with the science from my lab.

JCI: Can you describe your typical day?

Olson: I'm up by 6:00 a.m. and usually deal with mail from the day before, e-mails, and administrative paperwork before dropping one or more of my three kids off at school on the way to the lab. The first thing I do when I get to work is make the rounds looking for results someone may have generated the night before. Most of my day is spent talking with students and postdocs and working on papers. As a department chair, I also have administrative responsibilities, but I have a great staff that carries much of that load. I usually leave the lab by 6:00 p.m. to either drive kids in car pool or work out and get home in time for dinner with the family.

JCI: Are you a fan of country music?

Olson: I am indeed a fan of country music and have attended many Willie Nelson concerts. I also love the blues and rock

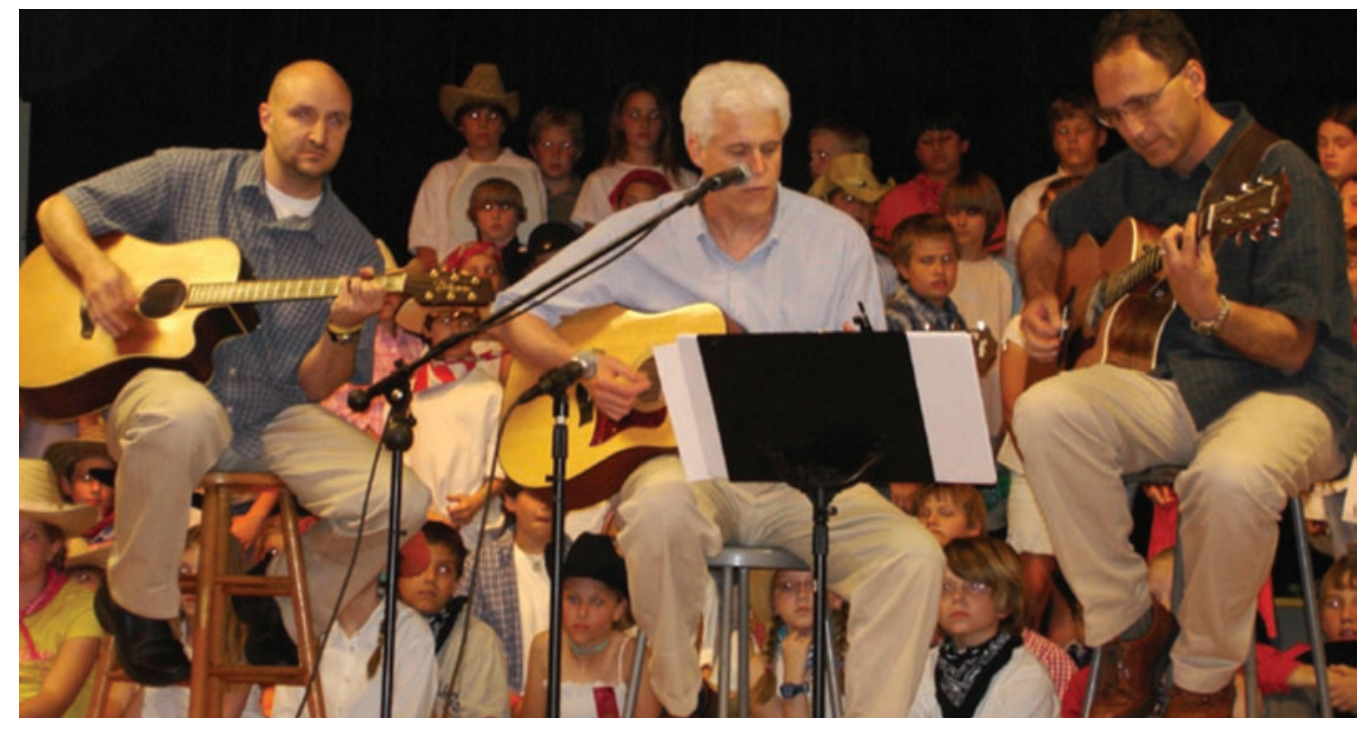

Eric Olson (center), the first Willie Nelson Professor, playing his own music with his band, the Transactivators. 
and roll. In my spare time, what little there is, I play guitar and harmonica in a group called the Transactivators with friends from my department. Inspired by the Willie Nelson Professorship, we are working on a new tune called "Mama, don't let your stem cells grow up to be cowboys".

JCI: At the end of your career, what do you hope to have accomplished?

Olson: My long-term goals are to create a blueprint for development of cardiac, skeletal, and smooth muscle cells and to use that knowledge to improve human health. Along the way, I hope to populate the field with outstanding, independent trainees and the next generation of scientific leaders.

\section{SB}

\section{Stopping stroke before it strikes}

$T_{1}$

he most common type of stroke, ischemic stroke, affects nearly 700,000 people per year, or 1 person every 45 seconds. Because stroke is notoriously difficult to treat, a sought-after approach is to find ways to avoid stroke before it can happen. To this end, the FDA recently approved the first blood test designed to predict a patient's risk of ischemic stroke.

The new test, called the PLAC test, can help identify at-risk patients so that preventative measures, such as lifestyle modification and treatment with daily aspirin and statins, can be taken.

The ability to forecast stroke is critical but has been challenging. The vascular changes that precede it develop stealthily and are not evident for a long time. "Stroke is by nature unpredictable," says Mark Fisher, chair of the Department of Neurology at University of California, Irvine.

And despite years of intense research, treatment for a person who has had a stroke is extremely limited.

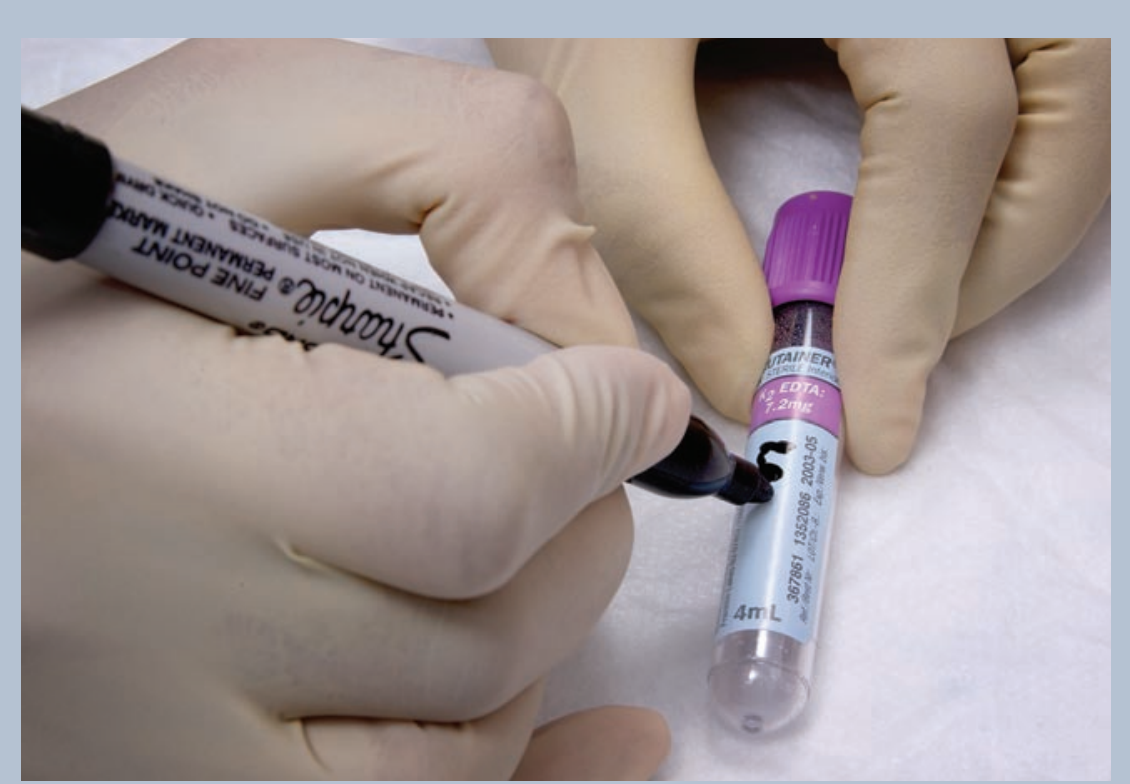

The new PLAC blood test can now predict a person's risk of stroke. Photo courtesy of

Centers for Disease Control.

"Stroke is hard to treat because we don't have any treatment," says Patrick Lyden, director of the Stroke Center at University of California, San Diego. "The other issue is that too few patients recognize stroke."

The only approved therapy for stroke is tissue plasminogen activator (tPA), which must be administered within a few hours and is considered controversial since it increases the risk of neuronal toxicity and bleeding in the brain when given improperly. Patients often don't get to the hospital in time for the currently recommended 3-hour window for tPA. The need for prompt treatment, Fisher notes, has led to the phrase "time is brain."

In fact, tPA only reaches $3 \%$ of stroke patients and is successful in only $10 \%$ of those recipients.

The PLAC blood test measures levels of an enzyme called lipoprotein-associated phospholipase A2 (Lp-PLA2), previously found to be predictive of coronary artery disease, which is associated with artery hardening and atherosclerosis and causes blockage of blood vessels, which can lead to stroke. Results from a large study by the National Heart Lung and Blood Institute, Atherosclerosis Risk in Communities, showed that people with elevated levels of LP-PLA2 have twice the risk of ischemic stroke over 6 to 8 years.

Traditional risk factors for stroke include diabetes, high blood pressure, smoking, atherosclerosis, and age. All of these can facilitate clot production in the blood vessels or support the growing thrombus once it is logged in the brain artery, says Berislav Zlokovic, associate chair of the Department of Neurological Surgery at the University of Rochester. Lp-PLA2 predicts stroke independently of these factors.

Some question the utility of the test in light of previous findings showing that levels of C-reactive protein (CRP), which increase upon inflammation of blood vessels, are elevated many years before stroke. A test for CRP levels has already been shown to predict stroke risk independently of other traditional risk factors.

Eng Lo, director of the Neuroprotection Research Laboratory at Harvard, points out that basic biochemistry suggests that CRP and LP-PLA2 are independent risk factors indicative of different arms of the inflammatory cascade. Despite lack of overlap, both tests would lead to the same outcome, he says, in terms of modifying behavior or taking pills. "So is there really a lot of added value with PLAC? How does the test relate to nonhemodynamic embolic strokes or hemorrhagic strokes?” Lo asks.

"There are not that many studies that have looked at Lp-PLA2 in stroke," Fisher says, and this is another limiting factor in the PLAC test. As for clinical utility, it is still too soon to tell.

\section{SB}

